\title{
EXTENSÃO UNIVERSITÁRIA: VIVÊNCIAS DO NÚCLEO DE VIDA SAUDÁVEL DA UESB ${ }^{1}$
}

\author{
Irlandia Maria Serra Negra Coelho Rocha \\ Celeste Dias Amorim ${ }^{3}$
}

\section{RESUMO}

Este estudo apresenta o relato de experiência de um ano de vivências com grupos de adultos, a partir de 45 anos, estabelecidos com a implantação do Núcleo de Vida Saudável (NVS) na Universidade Estadual do Sudoeste da Bahia (UESB), por meio da parceira com o Ministério do Esporte. Nesse programa, 556 pessoas distribuídas em 4 grupos participaram de atividades como recreação, atividade física, artes manuais, teatro, em que parte dos inscritos participou mais de uma atividade no Núcleo, e em consequência disso, 800 atendimentos, aproximadamente, foram realizados. Durante o desenvolvimento das atividades, observou-se uma melhoria na qualidade de vida das pessoas, como também o despertar da consciência de que esporte e lazer são direitos de todo cidadão.

Palavras-chave: Lazer. Atividade Física. Qualidade de Vida.

\footnotetext{
${ }^{1}$ Financiamento do Ministério do Esporte e da Universidade Estadual do Sudoeste da Bahia (UESB)

${ }^{2}$ Servidora lotada na PROEX/UESB, Coordenadora do Programa Repensando Nossa Juventude Acumulada. Doutoranda em Planificação Territorial e Gestão Ambiental (Universidade de Barcelona/UESB).E-mail: irlandiarocha@hotmail.com

${ }^{3}$ Mestranda do Programa de Pós-Graduação em Ciências Ambientais da UESB, Bolsista da FAPESB, colaboradora na execução do Núcleo de Vida Saudável. E-mail: celamorim@gmail.com

\begin{tabular}{l|l|l|l|l}
\hline Revista Extensão \& Cidadania & Vitória da Conquista & v. 1, n. 1 & p. 105-119 & jan./jun. 2013 \\
\hline
\end{tabular}
}




\title{
UNIVERSITY EXTENSION: experiences of the Center for Healthy Living UESB
}

\begin{abstract}
This study presents an account of the experience of one year of experiences with groups of adults from 45 years, established from the UESB deployed in the Center for Healthy Living, through partnership with the Ministry of Sports. Thus, 556 people distributed in four groups, participated in activities such as recreation, physical activity, arts and crafts, theater. Since part of the subscribers made more than one activity in the nucleus, thereby increasing the number of visits to approximately 800. During development there was a better quality of life and in raising public awareness that sport and leisure as a right of every citizen.
\end{abstract}

Keywords: Leisure. Physical activity. Quality of Life.

\section{Apresentação}

Em 2001 foi implantado na Universidade Estadual do Sudoeste da Bahia (UESB), campus de Vitória da Conquista, por intermédio da Pró-Reitoria de Extensão e Assuntos Comunitários, o Programa Repensando Nossa Juventude Acumulada, o qual, em 2009 e 2010 recebeu como parte integrante de suas ações o Núcleo de Vida Saudável (NVS).

O NVS, inserido no Programa Esporte e Lazer na Cidade (PELC), é uma parceria do Ministério do Esporte com a UESB, que foi lançado para a comunidade de Vitória da Conquista, em abril de 2009. Seu objetivo é oferecer esporte não competitivo, lazer e recreação para pessoas adultas, idosas e portadoras de necessidades especiais.

Durante 12 meses foram oferecidas 600 vagas no núcleo para as comunidades do entorno da UESB e dos bairros Alto Maron, URBIS II e URBIS VI de Vitória da Conquista, para a execução de ações por meio de atividades físicas, trabalhos manuais e teatroterapia. O público alvo era composto, em sua maioria, de mulheres acima de 45 anos, público dinâmico, alegre, frequente e que 
correspondia às atividades propostas. A procura dos indivíduos pelo projeto se deu basicamente pela promoção da saúde, do lazer e da sociabilidade, superando as expectativas, com aproximadamente 800 vagas ocupadas nas atividades, pois algumas pessoas participaram de mais de uma dessas ações.

Essa demanda é passível de compreensão quando se evidencia que, atualmente, tanto os hábitos pessoais e o estilo de vida como a inatividade física e a alimentação inadequada são itens que provocam impacto sobre a saúde. Nesse sentido, promover mudanças comportamentais pode prevenir o controle de doenças associadas a hábitos de vida errôneos.

\section{Objetivo}

O presente trabalho tem como principais objetivos, o desenvolvimento de atividades físicas, recreativas, esportivas e lúdicas, além de trabalhos manuais que possibilitem a promoção da saúde e o bem-estar de adultos e pessoas idosas.

Por meio de relatos de experiência (pesquisas feitas verbalmente) e questionários (PAR-Q ${ }^{4}$ e teste de qualidade de vida), busca-se constatar se a população alvo experimenta os benefícios do Programa, a fim de melhorar suas condições físicas e saúde em geral. Com base no desenvolvimento das atividades supracitadas, acrescentando as teatrais e artes manuais, pretende-se aumentar a flexibilidade, a resistência muscular, a coordenação, o equilíbrio, a criatividade e a execução do caráter lúdico dos participantes.

\section{Metodologia}

O método de trabalho se constitui de uma abordagem teóricoprática, fundamentada na pesquisa-ação e assistência convergente, com atividades de integração social. Para tanto, deve-se considerar o homem como sujeito e ator social do seu viver/envelhecer, mobilizando-o

\footnotetext{
${ }^{4}$ A aplicação do Questionário de Prontidão de Atividade Física (Physical Activity Readiness Questionnaire - PAR-Q) auxilia na identificação do grupo de adultos em que a prática de exercícios pode ser inadequada ou que inspira uma maior atenção do instrutor.
} 
para a construção de sua cidadania, por meio dos seguintes princípios norteadores: participação popular em movimentos organizados da comunidade; desenvolvimento do interesse comum e estímulo ao senso crítico da realidade cotidiana; qualidade de vida, pela melhoria das condições de saúde e educação direcionadas à plenitude de vida; coesão social, que fortalece a integração e o sentimento de solidariedade grupal. No desenvolvimento da experiência, foram atendidas pessoas em envelhecimento (maiores de 45 anos), residentes nos bairros Alto Maron, Bateias, Brasil, Guarani, URBIS II, URBIS III, URBIS VI, como também as comunidades rurais de Santa Marta e Vila do Bem Querer, do município de Vitória da Conquista.

Como estratégias utilizadas foram realizadas aulas expositivas e práticas, com apresentação de filmes, dinâmicas, como dança circular, jogos, relaxamento e finalizou-se com uma mensagem sobre o valor que tem o idoso na sociedade e estímulo à prática de atividade física. Houve também discussões sobre notícias da violência, com a abertura de espaço para que narrassem suas próprias vivências relacionadas ao tema; informação dos contatos que devem ser feitos em caso de efetivas agressões; exibição de filmes e palestras; passeatas que enfatizavam a inclusão e o respeito ao idoso e ao deficiente; feiras de saúde monitoradas por equipe multidisciplinar; passeio a outros ambientes; aplicação de exercícios que trabalham as regiões do corpo, nas quais os componentes mais se queixam de dores e cansaço; aplicação de técnicas que buscam a valorização da história cultural e/ou história de vida de cada membro.

Para cada semestre de atividades, foram planejados temas geradores:

- O Idoso, Cidade e Cidadania (período de abril a junho de 2009);

- O Idoso, Saúde e Bem-estar (período de julho a dezembro de 2009);

- Lazer, Atividade Física e Promoção de Saúde (período de janeiro a abril de 2010).

No ato de inscrição, o participante preencheu um questionário de qualidade de vida, o qual foi tabulado por meio da utilização do 
programa Excel. Os resultados obtidos nos níveis de nutrição, estresse, atividade física, relacionamento social e comportamentos preventivos foram representados graficamente pelo pentáculo do bem-estar, que corresponde a uma figura no formato de uma estrela. Esta figura foi desenhada para facilitar a visualização do estilo de vida do indivíduo e do grupo, sendo o estilo de vida um dos parâmetros na determinação da saúde das comunidades.

O acompanhamento pedagógico dos agentes e a base teórica deste texto tiveram as seguintes fontes: Brasil (2006a, 2006b), Costa (2000), Couto (2001), Greco e Brenda (1998), Patente Filho (1989), Garcia (2002) e Marcellino (1995).

\section{O projeto}

O NVS teve início com o I Módulo Capacitação para agentes sociais envolvidos, com a assistência de pessoas da comunidade e membro do Conselho Municipal do Idoso, representando o controle social do programa. O encerramento do módulo culminou com o Lançamento do Núcleo na Praça 9 de Novembro, com uma feira de saúde e atividades para a população.

Com o núcleo em andamento, realizando diariamente atividades físicas, de artesanato e de teatro, foram propostas ao grupo várias ações acolhidas e efetuadas, com participação significativa, como: encontro O Estatuto do Idoso; Café da manhã; Passeata - Aniversário da cidade; Passeio em fazenda (município de Anagé); Palestras sobre Nutrição, Segurança no trânsito, Meio ambiente e Reciclagem; Confraternização junina e natalina; Aniversariantes do mês; Desfile de primavera; Dia do Folclore, Dia do Idoso, Dia da Vovó; campanhas Um dia sem carro e Dia do desafio; Um dia de lazer no SESC; Feira de saúde; Oficina de papietagem; Passeio na Matinha (município de Itapetinga); apresentação teatral no projeto Estação Cultural da UESB. 


\section{Conhecendo o público alvo em cada espaço}

O campus da UESB, em Vitória da Conquista, localiza-se em área circunvizinha à zona rural, precisamente às comunidades: Assentamento Santa Marta e Vila Bem Querer, formadas por uma população carente com alto índice negativo de qualidade de vida (Figura 1).

Figura 1 - Alunos do grupo de ginástica da UESB, Vitória da Conquista

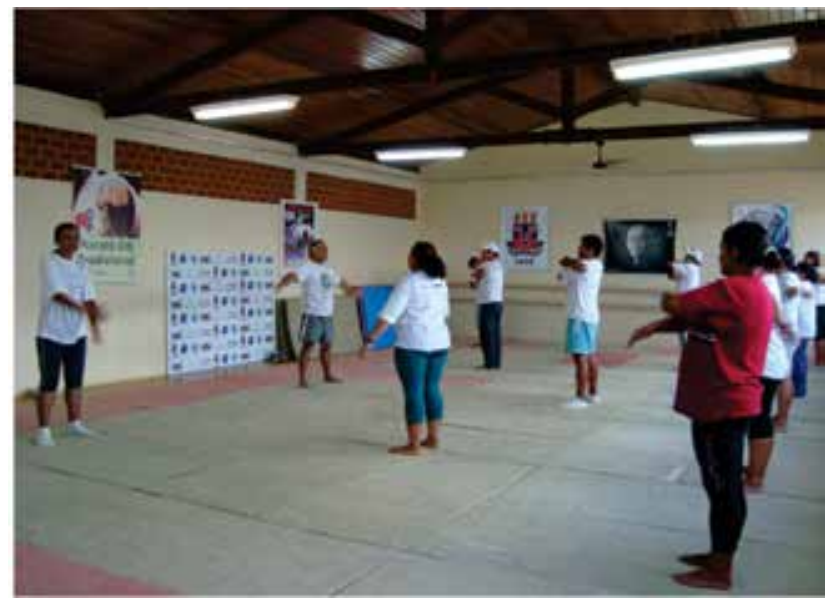

Fonte: Rocha (2010)

Os moradores inscritos correspondem a uma faixa etária de 45 a 83 anos, num universo de 69\% de mulheres e 31\% de homens; não há nenhum portador de necessidade especial, mas a aplicação do PAR-Q indicou que o grupo, como um todo, necessita de atenção especial. Eles apresentam dores em alguma parte do corpo, doenças como hipertensão (26\%) e diabetes (1\%), 26\% fazem dieta, $7 \%$ são fumantes, $10 \%$ ingerem álcool socialmente e têm como motivo de adesão ao grupo a prevenção, o condicionamento físico e o lazer.

A aplicação do questionário de qualidade de vida com tabulação, pelo pentáculo do bem-estar, indicou que os membros não têm uma boa nutrição, não fazem prática regular de atividade física e apresentam uma média preocupação com a prevenção de doenças. Seu relacionamento social e controle de stress mostram-se bons. Como membros de uma 
comunidade rural, ainda preservam o relacionamento diário com vizinhos e familiares, sendo este grupo apontado com médio índice de qualidade de vida no Núcleo de Vida Saudável (Figura 2).

Figura 2 - Pentáculo do bem-estar do grupo de ginástica da UESB, Vitória da Conquista.

\section{PENTÁCULO DO BEM-ESTAR}

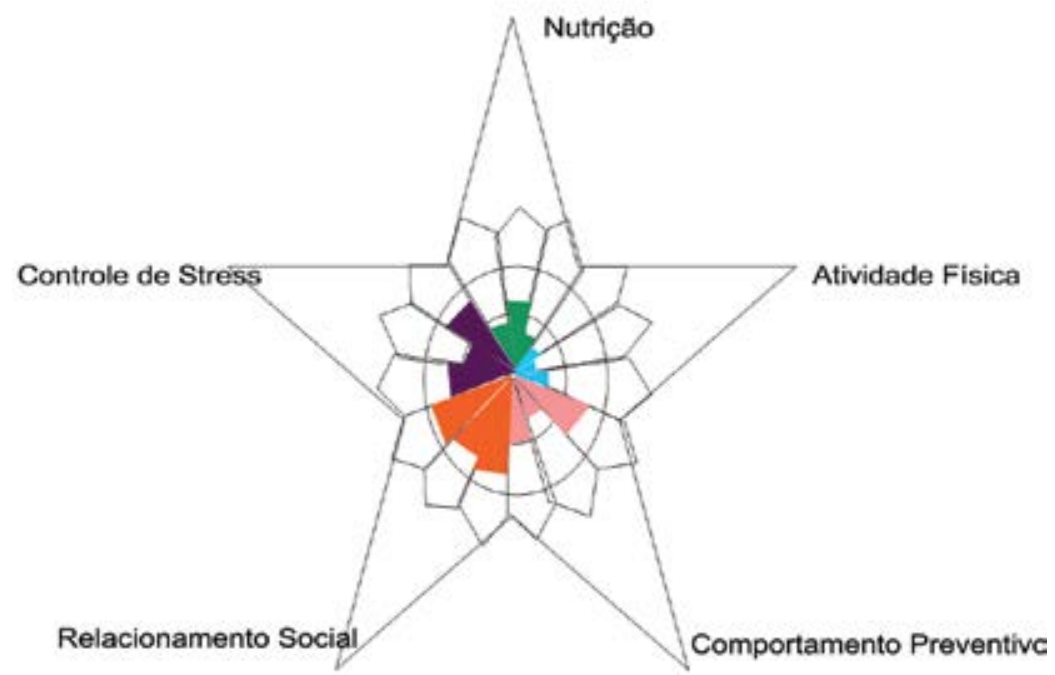

Fonte: Amorim (2010)

O Centro de Extensão e Assuntos Comunitários (CEAC), localizado na Praça Gerson Sales, bairro Alto Maron, é de fácil acesso, possui disponibilidade de espaços e conta também com a praça como ambiente opcional para a realização de atividades. Apesar de localizarse na "área nobre do bairro", nos períodos de estiagem sofre com a falta de água. Além disso, nas proximidades estão os bairros Pedrinhas, Guarani, Veloso e Nova Cidade, que com a parte mais alta do Alto Maron, formam um "perímetro de risco", onde ocorrem frequentes assaltos, prostituição, tráfico de drogas etc. (Figura 3). 
Figura 3 - Alunos do grupo de ginástica do CEAC, Vitória da Conquista.

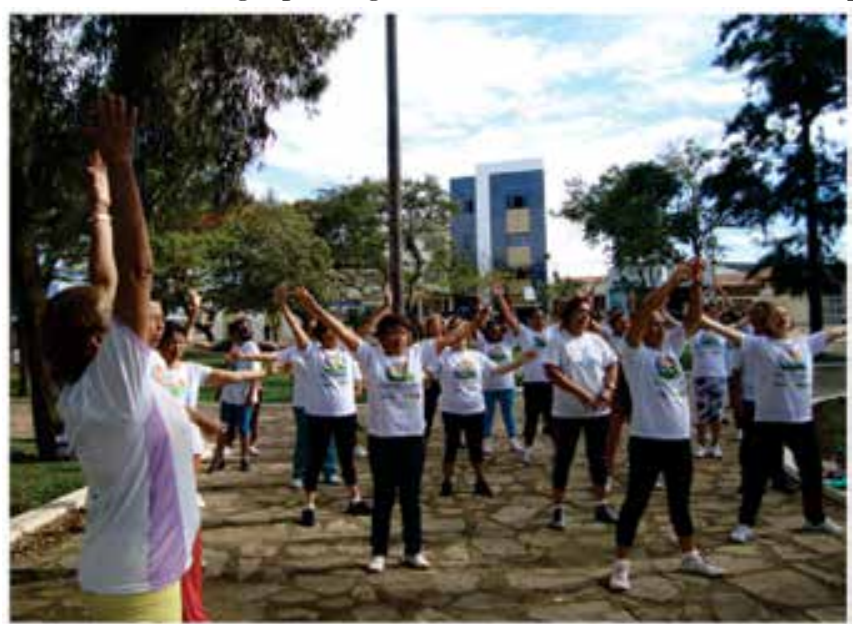

Fonte: Rocha (2010)

Os moradores inscritos correspondem a uma faixa etária de 45 a 84 anos, num universo de 97\% de mulheres e 3\% de homens; 3\% são portadores de necessidades especiais, mas a aplicação do PAR-Q indicou que 41\% do grupo necessitavam de atenção especial. No geral, apresentam dores em alguma parte do corpo, doenças como hipertensão (18\%) e diabetes (5\%); 15\% fazem dieta; 6\% são fumantes; $8 \%$ ingerem álcool socialmente e têm como motivos de adesão ao grupo o condicionamento físico, a prevenção, a estética e o lazer.

A Casa de Convivência do Idoso (CCI) é um espaço oferecido pela Prefeitura Municipal de Vitória da Conquista para o Projeto Vivendo a Terceira Idade (PVTI, composto de 08 grupos de $3^{\text {a }}$ idade), onde são proporcionadas várias atividades em espaços adequados e adaptados ao idoso, mediante parcerias com a comunidade. O NVS, assim, é parceiro com a realização do Curso de Teatro, o qual é denominado Grupo Liberdade Teatral.

A aplicação do questionário de qualidade de vida com tabulação, pelo pentáculo do bem-estar, indicou que os membros não têm uma boa nutrição e não faziam prática regular de atividade física, com boa preocupação com a prevenção de doenças, bom relacionamento social 
e controle de estresse regular. Como membros de uma comunidade de área de risco, há uma resistência no relacionamento diário com vizinhos e uma preocupação na sobrevivência do dia a dia, intensificando ainda mais o fator estresse. Esses fatores apontam o grupo com um médio índice de qualidade de vida indicado no Núcleo de Vida Saudável (Figura 4).

Figura 4 - Pentáculo do bem-estar do grupo de ginástica do CEAC, Vitória da Conquista.

\section{PENTÁCULO DO BEM-ESTAR}

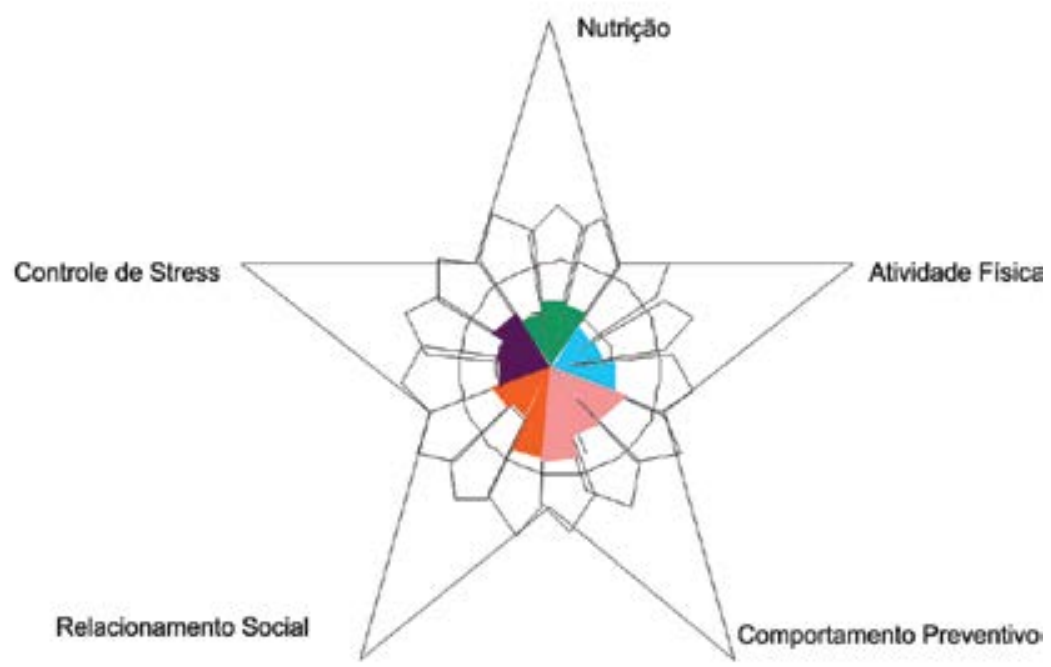

Fonte: Amorim (2010)

O Centro Social Urbano (CSU) localiza-se na URBIS II, com adjacências aos bairros Brasil, Bateias e URBIS III. Apresenta uma clientela bem diversificada quanto à idade, ao nível social e econômico etc. Possui espaços adequados às atividades como quadra, campo de futebol, salas para artesanato e atividade física (Figura 5). 
Figura 5 - Alunos do grupo de ginástica do CSU, Vitória da Conquista.

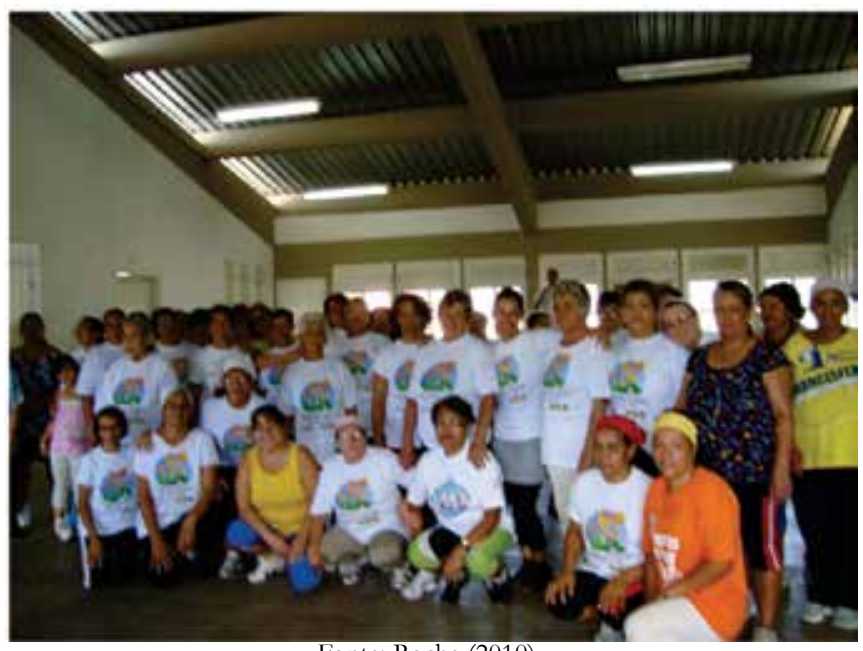

Fonte: Rocha (2010)

Os moradores inscritos correspondem a uma faixa etária de 45 a 89 anos, num universo de 99\% de mulheres e 1\% de homens; 4,4\% são portadores de necessidades especiais, mas a aplicação do Par-Q indicou que 33\% do grupo necessitam de atenção especial. No geral, apresentam dores em alguma parte do corpo, doenças como hipertensão (20\%) e diabetes (6\%); 8\% fazem dieta; 3\% são fumantes; 3\% ingerem álcool socialmente, tendo como motivos de adesão ao grupo o condicionamento físico, a prevenção, a estética e o lazer.

A aplicação do questionário de qualidade de vida com tabulação, pelo pentáculo do bem-estar, indicou que os membros têm boa nutrição e prática regular de atividade física, com média preocupação com o relacionamento social e com a prevenção de doenças, além de bom controle de estresse. O grupo apresentou um melhor nível no que concerne ao fator socioeconômico e educacional, demonstrou ser uma comunidade participativa e com uma boa interação entre seus membros e os problemas locais do bairro, onde ainda se preserva o 
relacionamento diário com vizinhos e familiares. Estes fatores revelam um dos melhores índices de qualidade de vida indicados no NVS (Figura 6).

Figura 6 - Pentáculo do bem-estar do grupo de ginástica do CSU, Vitória da Conquista.

\section{PENTÁCULO dO BEM-ESTAR}

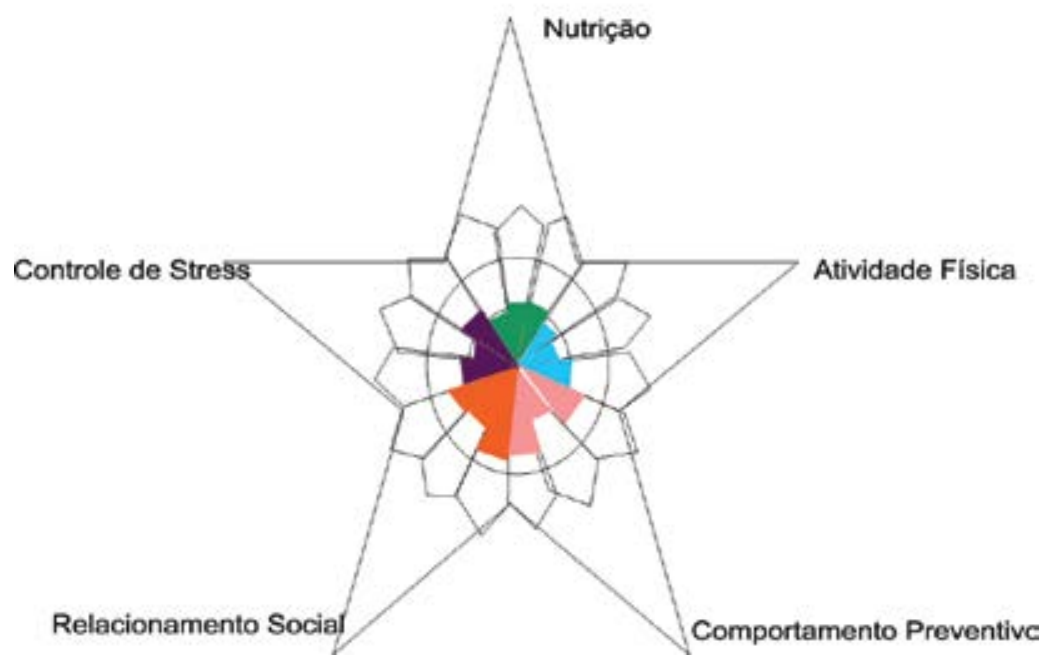

Fonte: Amorim (2010)

A Escola Poliana da rede particular de ensino, por dispor de espaço, abre as portas para trabalhos sociais junto à comunidade local. Está situada na Urbis VI, tendo como bairros adjacentes o Morada Real e o Vila América, sendo os três bairros populosos e carentes (Figura 7).

Os moradores inscritos correspondem a uma faixa etária de 45 a 74 anos, num universo de 100\% de mulheres; 6\% são portadores de necessidades especiais, mas a aplicação do Par-Q indicou que $47 \%$ do grupo necessitam de atenção especial. No geral, apresentam dores em alguma parte do corpo, doenças como hipertensão (17\%) e diabetes (11\%); $14 \%$ fazem dieta; $5 \%$ são fumantes; $6 \%$ ingerem álcool socialmente, tendo como motivos de adesão ao grupo o condicionamento físico, a prevenção de doenças, o lazer e a estética. 
Figura 7 - Alunos do grupo de ginástica do Urbis VI, Vitória da Conquista.

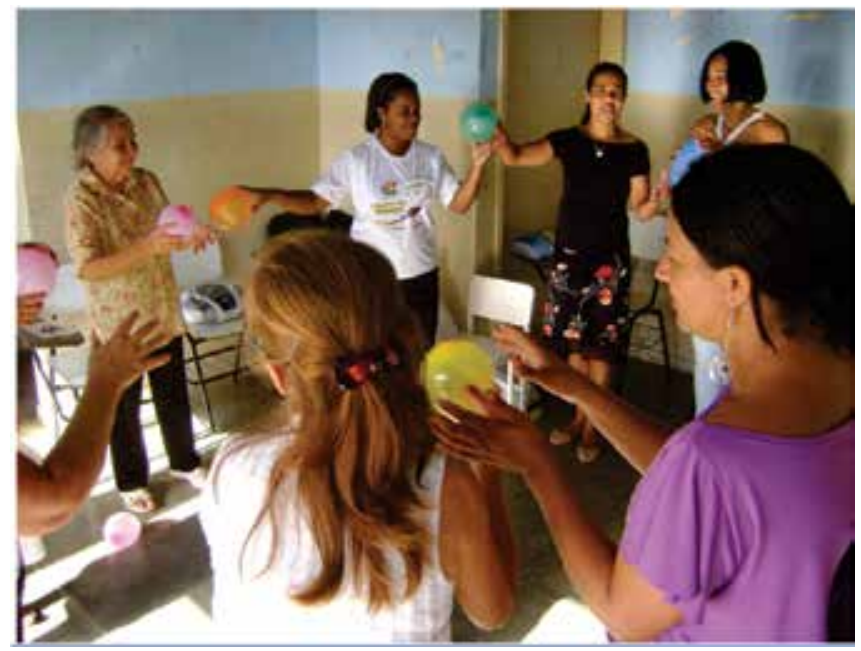

Fonte: Rocha (2010)

A aplicação do questionário de qualidade de vida com tabulação, pelo pentáculo do bem-estar, (Figura 8) indicou que os membros têm uma boa nutrição, mas não faziam prática regular de atividade física. Além disso, os dados evidenciaram uma média preocupação com o relacionamento social e com a prevenção de doenças, conquanto, apresentaram um bom controle de estresse. Como membros de uma comunidade formada por bairros novos e populosos, destaca-se a união local para tentar levar o bairro para regiões periféricas de Vitória da Conquista, com menos violência. Assim, a comunidade luta contra a entrada de traficantes e prostituição infantil no bairro, preservando o relacionamento diário com vizinhos e familiares. A totalidade destes fatores, apontados pelo grupo e registrados no pentáculo do bem-estar, indica um dos melhores índices de qualidade de vida no NVS. 
Figura 8 - Pentáculo do bem-estar do grupo de ginástica da Urbis VI, Vitória da Conquista.

\section{PENTÁCULO DO BEM-ESTAR}

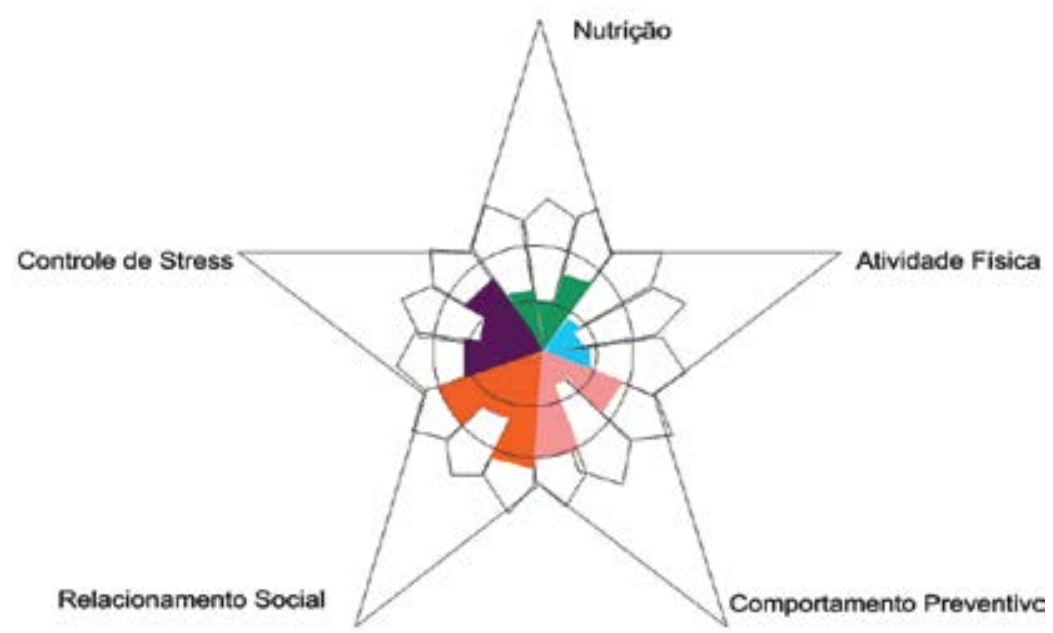

Fonte: Amorim (2010)

\section{Considerações Finais}

Servindo-se dos instrumentos de coleta de dados, pode-se estabelecer um estudo diagnóstico de cada espaço de atuação do Núcleo de Vida Saudável, percebendo-se uma comunidade heterogênia, com problemas locais distintos, o que leva à mudança do foco de execução das atividades nos espaços.

O pentáculo do bem-estar indicou de boa a média qualidade de vida em ambas as comunidades (rural e urbana). Na urbana, registrou um maior índice de violência e na rural uma qualidade de vida mais baixa do que na primeira, porém com melhor controle de violência e índice socioeconômico e educacional.

Segundo relatos, após o primeiro trimestre de execução do projeto e do Módulo de Avaliação, pode-se perceber a influência positiva que o Núcleo de Vida Saudável ofereceu a esses grupos, ao 
aumentar o índice de qualidade de vida dos grupos favorecidos pelo projeto.

Quanto aos resultados quantitativos, também são positivos, vez que as 600 vagas ofertadas foram preenchidas por 556 pessoas (relacionadas em mídia em anexo). É importante registrar que parte dos inscritos fez mais de uma atividade no Núcleo, obtendo assim, aproximadamente, 800 vagas ocupadas nas atividades.

Consideramos positivos os resultados qualitativos por terem sido impactantes na melhoria da qualidade de vida das pessoas, no despertar da consciência de que esporte e lazer são direitos de todo cidadão, por terem contribuído para fortalecer a cultura local e criar hábitos saudáveis, além de remeterem ao fortalecimento da cidadania dos participantes. Tais resultados estimularam a convivência e o trabalho coletivo, e suscitaram um novo Projeto da Pró-Reitoria de Extensão e Assuntos Comunitários da UESB, intitulado "Mãos Empreendedoras: cooperativismo e sustentabilidade", por meio do artesanato; nos núcleos onde se desenvolveram o projeto houve melhoria na utilização dos equipamentos de esporte e de lazer, criação de grupos culturais de teatro com participantes do projeto (pessoas idosas), os quais apresentaram um ótimo desempenho.

Diante do que foi exposto, nota-se que os trabalhos das atividades direcionadas, tomando-se por base o estilo de vida de forma integrada, estabeleceram nos indivíduos uma sensação de bem-estar e, certamente, a proposta do Núcleo de Vida Saudável em proporcionar uma qualidade de vida foi atingida, pois a experiência do componente em um ano possibilitou uma conscientização sobre a prevenção e a necessidade de continuar a manutenção dessa mudança de atitude em busca da Vida Saudável. 


\section{Referências}

BRASIL. Ministério do Esporte. Fundamentação sobre o Sistema Nacional do Esporte e Lazer. Brasília: ME, 2006a.

BRASIL. Ministério do Esporte. Política nacional do esporte. Brasília: ME, 2006b.

COSTA, A. C. G. Ideário do programa de educação pelo esporte. São Paulo: Instituto Ayrton Senna, 2000.

COUTO, A. C. P. Referencial teórico do Projeto Guanabara: conteúdos da Educação Física a serem desenvolvidos nos projetos de educação pelo esporte. In: GARCIA, E. S.; LEMOS, K. L. M. Temas atuais VI. Educação Física e Esportes. Belo Horizonte: Health, 2001.

GARCIA, R. P. Contributo para uma compreensão do desporto: uma perspectiva cultural. In: . Esporte e atividade física - interação entre rendimento e saúde. São Paulo: Manole, 2002.

GRECO, P. J.; BENDA, R. Iniciação esportiva universal. Belo Horizonte: Ed. da UFMG, 1998.

MARCELLINO, Nelson Carvalho. Lazer e educação. 3. ed. São Paulo: Papirus, 1995.

PARENTE FILHO, Marcos Santos (Org.). Esporte, educação física $e$ constituição. São Paulo: IBRASA, 1989. 